\title{
Remote Sensing Methods for the Retrieval of Inventory and Bioproductivity Parameters of Forests Using High Resolution Satellite Images
}

\author{
Egor Dmitriev ${ }^{1, *}$, Vladimir Kozoderov ${ }^{2}$, Sergey Donskoy ${ }^{3}$, Petr Melnik ${ }^{4}$, and Anton Sokolov ${ }^{5}$ \\ ${ }^{1}$ Institute of Numerical Mathematics of Russian Academy of Sciences, ul. Gubkina 8, 119333 \\ Moscow, Russia \\ ${ }^{2}$ M.V. Lomonosov Moscow State University, Leninskiye Gory 1, 119991 Moscow, Russia \\ ${ }^{3}$ Federal Forestry Agency ROSLESINFORG, Volgogradsky Prospect, 45- 1, 109316 Moscow, Russia \\ ${ }^{4}$ Mytischi Branch of Bauman Moscow State Technical University, 1st Institutskaya street 1, 141005 \\ Mytischi, Moscow region, Russia \\ ${ }^{5}$ Laboratoire de PhysicoChimie de l'Atmosphère Université du Littoral Cote d'Opale, Avenue Maurice \\ Schumann 189A, 59140 Dunkerque, France
}

\begin{abstract}
A method for automated processing high spatial resolution satellite images is proposed to retrieve inventory and bioproductivity parameters of forest stands. The method includes effective learning classifiers, inverse modeling, and regression modeling of the estimated parameters. Spectral and texture features are used to classify forest species. The results of test experiments for the selected area of Savvatievskoe forestry (Russia, Tver region) are presented. Accuracy estimates obtained using ground-based measurements demonstrate the effectiveness of using the proposed techniques to automate the process of updating information for the State Forest Inventory program of Russia.
\end{abstract}

\section{Introduction}

The State Forest Inventory (SFI) is the key element of forest inventory work. Using SFI materials in medium- and long-term planning document development will help make informed decisions on forest management. A network of permanent inventory plots of constant radius is created to determine quantitative and qualitative characteristics of forests and systematic monitoring of their health.

The materials of the forest inventory, updated for forest growth course and according to Earth remote sensing data, are used to build a network of permanent inventory plots. Last forest inventory maps being vectorized with current changes, digital base material is created for all the targets. After making the current changes from the forest inventory maps, the digital base materials are updated according to Earth remote sensing data.

In most cases when updating it is only a matter of contour satellite image interpretation and detection of unaccounted logged areas, areas of forest destruction and crowing forest fires. However, for the intensive forest management areas it is necessary to retrieve the

\footnotetext{
* Corresponding author: yegor@mail.ru
} 
extended information on young forests, selective logging areas and forests that do not get forest inventory by using satellite images of higher resolution (up to $0.5 \mathrm{~m}$ ).

The results presented in this paper are based on processing images of the commercial satellite system WorldView-2. The system contains an eight-channel multispectral camera with $1.84 \mathrm{~m}$ resolution and a panchromatic camera with $0.46 \mathrm{~m}$ resolution. Scientific studies presented in recent publications demonstrate that WorldView-2 images can be used effectively to determine various characteristics of stands, in particular, their leaf area index [1] and species composition [2].

Adoptions of the new Forest Code of the Russian Federation and influence of political and economic factors have dramatized the situation with relevance of forest inventory. Annual volume of forest inventory work has fallen by $80 \%$. The issue of strategic forest management planning, as well as the sectoral reporting in the framework of international agreement implementation, including carbon sequestration, has risen sharply. Remote inventory methods make it possible to significantly increase the SFI efficiency, since currently large forest areas of the Russian Federation are not wired with an inventory plot network. Moreover, ground-based methods for forest inventory are considered timeconsuming and expensive.

\section{The method of remote inventory automation}

Species composition and age classes of mixed stands are determined by learning classification methods. The classifier proposed in this work is an effective modification of the well-known Error Correcting Output Codes (ECOC) classifier [3]. The ECOC allows solving multi-class classification problem by a series of binary classifications and sequent voting. The general ECOC scheme is as follows. Each class is assigned a unique code (vector string) containing numbers $1,-1$, and 0 . Class codes have the same specified length and can be combined into a coding matrix whose strings correspond to recognizable classes, and columns - to different methods of some binary classifier's learning. To ensure that a classification problem can be successfully solved any of two classes must have a coding matrix column which these classes are separated in.

At the decoding stage binary classification problems determined by coding matrix columns are solved. Binary classifiers' responses are written into a row vector. Next the distances between the received string and the class codes in the sense of some given measure are calculated. The class corresponding to the minimum distance is the ECOC response.

Standard classification algorithms of different complexity and computational efficiency are used as basic binary classifiers. Nonlinear classifiers usually have an advantage in accuracy due to application of more complicated discriminant surfaces. At the same time, they lose in speed and sustainability of learning outcomes. The ECOC allows us to construct an effective combination of these algorithms [4].

Spectral brightness of separate image pixels normalized to integrated brightness is considered as a spectral feature. This transformation can significantly reduce the spread resulting from brightness difference. Textural features are based on the gray-level cooccurrence matrix statistics (GLCM). The GLCM is calculated for some small rectangular area of the original image centered on the classified pixel. The GLCM elements are frequencies of occurrence of brightness gradients along a given direction. Contrast, correlation, energy and uniformity are used as statistics. These statistics can be calculated for several directions.

Combination of textural and spectral features, even in the case of multispectral images, forms high dimensional space. When using standard classification methods, we inevitably come to curse of dimensionality problem or useful information loss. In this paper we 
propose a method that should solve this problem. The concept of this method is represented in Fig. 1.

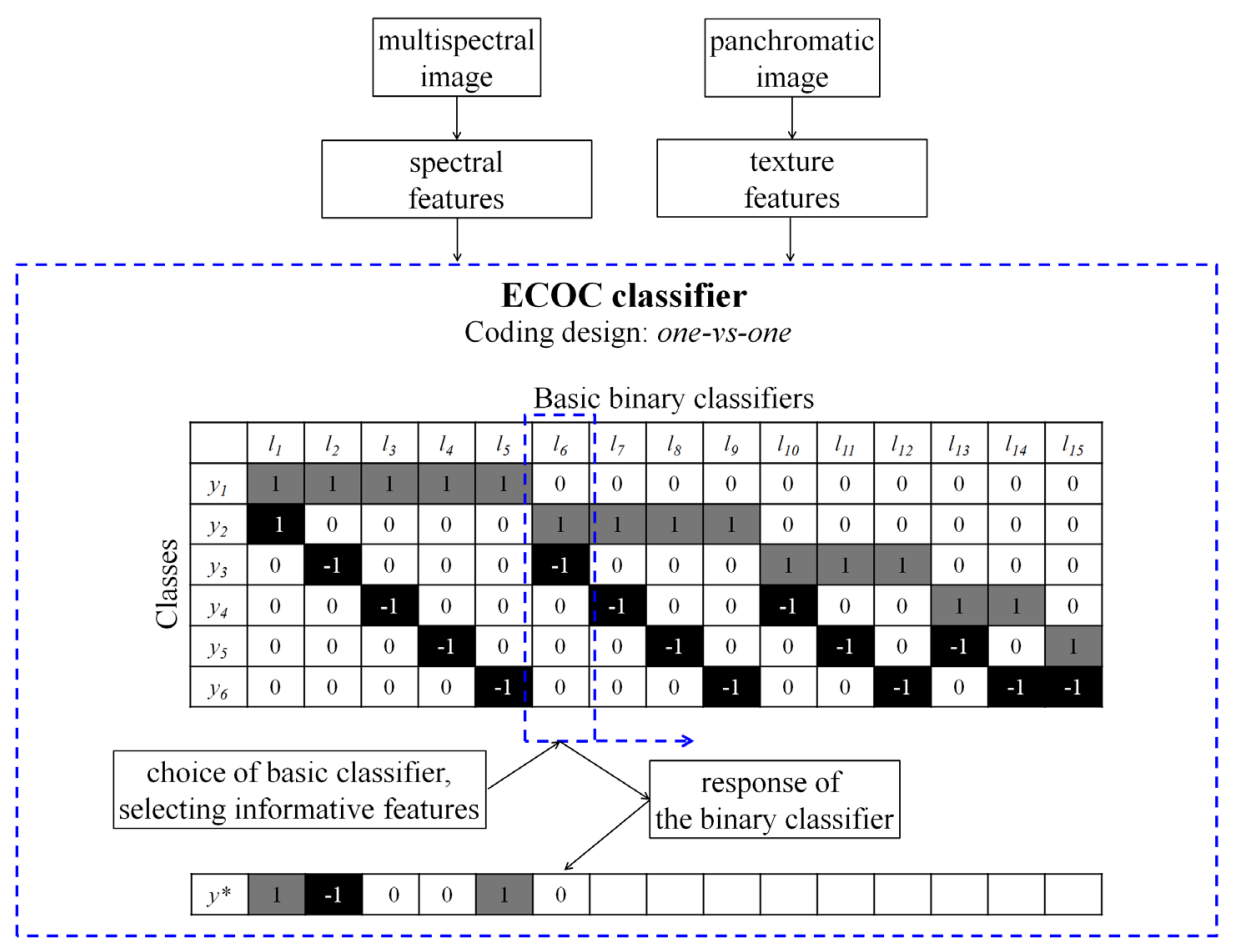

Fig. 1. The scheme of the classification method used for the recognition of ground objects based on spectral and textural features. Here $y_{i}$-names of classes, $l_{i}$ - labels of binary classifiers, $y^{*}-$ label of a classified object.

The ECOC uses a coding matrix corresponding to one-vs-one strategy. The rationale for this choice is presented in [4]. For each binary classification problem a basic algorithm is selected to ensure maximum classification rate without significant loss of accuracy. Basic classification algorithms should not produce significant extrapolation beyond a learning set, i.e. refused classification is realized for each of them. For each binary classification problem an optimal set of features is selected using the regularized stepwise method [5].

For the retrieval of stands' bioproductivity parameters, we use an approach based on inverse modeling of remotely measured spectral intensity of solar radiation reflected by forest canopy. Currently there are different models of forest canopy reflectivity that differ in complexity. Earlier in [6] we proposed a model of forest canopy based on its projection parameters of canopy and crown density. The model considers reflection of direct and scattered radiation from the surface of tree leaves visible from above, reflection from intercrown vegetation and multiple reflection between tree leaves and intercrown vegetation with account for shadows in the intercrown area and tree crowns.

Inverse modeling is based on the look-up table method, which contains the spectral characteristics of forest canopy with typical values of stand parameters. The projection characteristics obtained are associated with stand fraction biomass and net primary production (NPP), based on the statistical models calibrated by ground-based measurements. Particularities of the use of this model for the processing of high spatial resolution images are presented in [7]. 


\section{Numerical experiments and discussion}

The subject of research is the territory of the Savvatyevskoe forestry of the Tver region. It is located in the south-eastern part of the Tver region in the Kalinin administrative district over 15.7 thousand hectare area. The forest stands of the Savvatyevskoe forestry are referred to the mixed coniferous broadleaf forest zone, to the area of mixed coniferous broadleaf forests of the Russian Federation. The main dominant species in the forestry are Pine, Spruce and Birch.

In 2007 the Tver forest inventory enterprise (currently the Tver branch of FSBI "Roslesinforg") carried out forest inventory in this forestry. Forest inventory was conducted first-class by ocular estimate with a $1 \mathrm{x} 1 \mathrm{~km}$ net of rides. The survey engineers did full-scale work describing stand composition, forest density, mean diameters, height, average annual stand depletion and other forestry indices. As a result of the forest inventory we have a forestry database which contains all the information about the forest health.

In 2009 SFI work was carried out in the Tver forestry of the Tver region. A series of work was done to create a digital base material, to make changes from forest inventory maps and to update the influence of natural and antropogenic factors by Earth remote sensing. Permanent inventory plots were formed and their data was compiled with the rest data from the permanent inventory plots of the Tver region and was submitted for processing.

The results of the WorldView-2 image classification of the Savvatyevskoe forestry are shown in Fig. 2. The black lines indicate the boundaries of the forest plots. The results obtained correlate well with the ground data of species composition and the visual test data of the test area objects.

The classification error estimates are presented in Table 1. The table rows correspond to true classes and the columns, with the exception of the last two, correspond to the classifier's responses. The last two columns contain relative errors obtained by the reclassification method (RCM) and by the cross-validation method (CVM). RCM is considered as a prior estimate of the classification error, since learning and test ensembles coincide in its calculation. When calculating CVM, test data is not involved in learning, and it is regarded as an independent estimate of the classification error. Close agreement of RCM and CVM indicates that there are no problems with relearning and curse of dimensionality.

It is easier to classify water bodies, soils and artificial objects. Classification error probability is less than $1 \%$. Individual pixels of these objects can be misclassified as a pine stand. This is apparently due to the presence of spectral characteristics corresponding to significant intercrown gaps typical for mature and overmature stands. Error probability in recognition of pine stands and meadow vegetation also does not exceed $1 \%$. Meadow vegetation can be misclassified as a pine or birch stand. It is possible to see high discriminability of coniferous stands, small-leaved stands and meadow vegetation. The greatest errors occur when recognizing aspen stands. Total misclassification probability is less than $5 \%$.

When determining bioproductivity parameters of stands it is necessary to have information about projective characteristics and species composition as well as about age and the cite index. Age classes can also be recreated using remote sensing data; however the errors will be much higher than in tree species definition. For the remote retrieval of the cite index it is necessary to make aerial lidar measurements of crown height and diameter, otherwise the cite index would be considered unchanged and the age classes would be updated by ground data. 


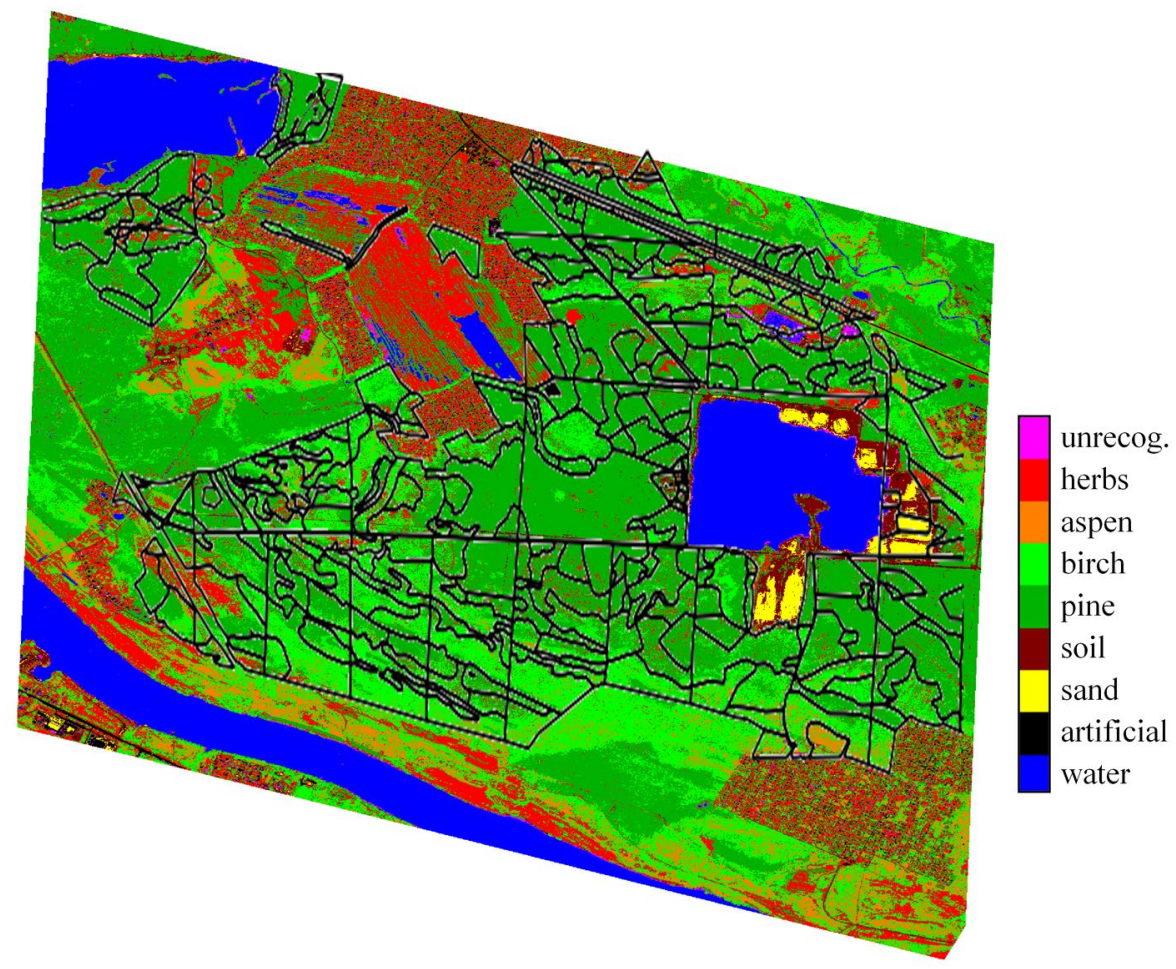

Fig. 2. The results of subject image processing WorldView-2 for the test tract in the Savvatyevskoe forestry.

Table 1. The results of classification error estimate of the WordView-2 multispectral images for basic types of objects in the test area.

\begin{tabular}{|l|l|l|l|l|l|l|l|l|l|}
\hline & Water & Artificial & Soils & Pine & Birch & Aspen & Herbs & RCM & CVM \\
\hline Water & 2483 & 0 & 0 & 1 & 0 & 0 & 0 & 0 & 0.0004 \\
\hline Artificial & 0 & 594 & 0 & 5 & 0 & 0 & 0 & 0 & 0.0083 \\
\hline Soils & 0 & 0 & 746 & 2 & 0 & 0 & 0 & 0 & 0.0027 \\
\hline Pine & 0 & 0 & 0 & 6052 & 43 & 0 & 11 & 0.0039 & 0.0088 \\
\hline Birch & 0 & 0 & 0 & 11 & 1844 & 133 & 12 & 0.0664 & 0.0780 \\
\hline Aspen & 0 & 0 & 0 & 0 & 187 & 795 & 0 & 0.1284 & 0.1904 \\
\hline Herbs & 0 & 0 & 0 & 10 & 6 & 0 & 1888 & 0.0031 & 0.0084 \\
\hline
\end{tabular}

The estimates of biomass give forest fractions (leaves/needles, branches, etc.)obtained for the Savvatyevskoe forestry test areas vary widely. Birch stand leaves have a 2.5-4 t/ha biomass, and pine stand needles have a 7-8 t/ha biomass. Typical averaged NPP values are $350-450 \mathrm{~g} /\left(\mathrm{m}^{2}\right.$ year $)$. The highest values correspond to deciduous forest stand. Forest plots with a majority of birches and high values of canopy density have NPP values of 550$600 \mathrm{~g} /\left(\mathrm{m}^{2}\right.$ year $)$. Pine forests have NPP from 50 to $350 \mathrm{~g} /\left(\mathrm{m}^{2}\right.$ year $)$. Dense stands have the 
highest values. Quantitative validation of biomass estimates and NPP productivity of stands is difficult. These results generally correspond to the estimates obtained by different authors at a global scale. A nuanced analysis of the bioproductivity parameter recovery results is given in [7].

\section{Conclusion}

Based on the analysis of the results obtained we can conclude that the proposed method for the retrieval of inventory and bioproductivity parameters of forests can be used to update attributive information on the forest stands structure taken from the permanent inventory plots. Considering the location of the Savvatyevskoe forestry, the method can be applied to other coniferous broadleaf stands during forest inventory activities within the framework of SFI in the Russian Federation.

This work was supported by the Russian Science Foundation (project No. 16-11-00007) and the RFBR (projects No. 14-05-00598 and 14-07-00141).

\section{References}

1. J. Tian, L. Wang, X. Li, H. Gong, C. Shi, R. Zhong, X. Liu, International Journal of Applied Earth Observation and Geoinformation. 61, 22-31 (2017).

2. M. Karlson, M. Ostwald, H. Reese, H.R. Bazié, B. Tankoano, International Journal of Applied Earth Observation and Geoinformation, 50, 80-88, (2016).

3. T.G. Dietterich, G. Bakiri, Journal of Articial Intelligence Research, 2, 263-286 (1995).

4. .V. Dmitriev, V.V. Kozoderov, . . Dementiev, .N. Safonova, Optoelectronics, Instrumentation and Data Processing, 54(3), 213-221, (2018).

5. .V. Dmitriev, Earth Exploration from Space, 3, 22-32 (2013).

6. V.V. Kozoderov, T.V. Kondranin, V.S. Kosolapov, V.A. Golovko, .V. Dmitriev, Issledovanie Zemli iz Kosmosa, 1, 57-65 (2007) (in Russian).

7. V.V. Kozoderov, .V. Dmitriev, Issledovanie Zemli iz Kosmosa, 6, 75-88, (2017) (in Russian).

8. A.Z. Shvidenko, S. Nilsson, V.S. Stolbovoy, et al, Russian Journal of Ecology, 2, 8390 (2001).

9. S.T. Gower, O. Krankina, M. Olson, M. Apps, S. Linder, C. Wang, Ecological Applications, 11, 1395-1411 (2001). 